\title{
DECOMPOSIÇÃO E LIBERAÇÃO DE NITROGÊ NIO DE RESÍDUOS CULTURAIS DE PLANTAS DE COBERTURA EM UM SOLO DE CERRADO(1)
}

\author{
J osé L uiz Rodrigues Torres ${ }^{(2)}$, Marcos Gervásio Pereira(3), Itamar \\ Andrioli ${ }^{(4)}$, J osé Carlos Polidoro ${ }^{(5)}$ \& Adelar J osé Fabian ${ }^{(6)}$
}

\begin{abstract}
RESUMO
A produção de massa seca, a taxa de decomposi ção e a liberação de nitrogênio (N) foram avaliadas em um experimento com sete tipos de cobertura vegetal: milheto pérola (Penni setum americanum sin. ti phoydes), braquiária (Brachiaria brizantha), sorgo forrageiro (Sorghum bicol or L. Moench), guandu (Cajanus cajan (L.) Millsp), crotalária juncea (Crotalarea juncea) e aveia-preta (Avena strigosa Schreb), em pousio e em área de cultivo convencional (testemunha), em solo de cerrado, em Uberaba, região do Triângulo Mineiro. Dentre as coberturas avaliadas, o mi lheto e a crotalária foram as que apresentaram a maior produção de massa seca, maior acúmulo e a maior liberação de N. A braquiária foi a cobertura que apresentou a maior taxa de decomposição. Todas as coberturas apresentaram a maior taxa de li beração de $\mathbf{N}$ até $\mathbf{4 2}$ dias após dessecação.
\end{abstract}

Termos de indexação: cultura de cobertura, reciclagem de nitrogênio, gramínea, leguminosa, mineralização de $\mathbf{N}$.

(1) Parte da Tese de Doutorado do primeiro autor, apresentada à Universidade Estadual Paulista - UNESP. Recebido para publicação em janeiro de 2004 e aprovado em maio de 2005.

(2) Professor Dr. Centro Federal de Educação Tecnológica de Uberaba - CEFET-Uberaba. Av. Edílson Lamartine Mendes 300, CEP 38045-000 Uberaba (MG). E-mail: jlrtorres@cefetuberaba.edu.br

(3) Professor Dr. Departamento de Solos da Universidade Federal Rural do Rio de J aneiro - UFRRJ . BR 465 Km 7, CEP 23890-000 Seropédica (RJ ). E-mail: gervasio@ufrrj.br

(4) Professor Dr. Departamento de Solos e Adubos da Universidade Estadual Paulista - UNESP. Via de acesso Professor Paulo Donato Castellane, Km 5, CEP 14884-900 J aboticabal (SP).

(5) Professor Dr. Departamento de Fitotecnia, UFRRJ.E-mail: polidoro@ufrrj.br

(6) Professor Dr. Centro Federal de Educação Tecnológica de U beraba, CEFET-U beraba. E-mail: fabian@cefetuberaba.edu.br 


\title{
SUMMARY: COVER CROPS RESIDUE DECOMPOSITION AND NITROGEN RELEASE IN A CERRADO SOIL
}

\begin{abstract}
Dry mass production, decomposition rateand nitrogen $(\mathrm{N})$ releasewereevaluated in a field experiment under seven cover crop types: pearl millet (Pennisetum americanum sin. typhoides), brachiaria grass (Brachiaria brizantha), sorghum (Sorghum bicolor L. M oench), pigeon pea (Cajanus cajan (L.) Mill sp), sunn hemp (Crotalaria juncea) and black oat (Avena strigosa Schreb), compared to a fallow and a traditional cropping system (control) in a cerrado soil (Uberaba-MG, Brazil). Among the tested cover crops, pearl millet and sunn hemp presented higher dry mass yield and nitrogen accumulation and release. Brachiaria grass had thehighest decomposition rateand shortest half-lifetime. All crops reached the highest $\mathrm{N}$ liberation rate 42 days after desiccation.
\end{abstract}

Index terms: cover crop, nitrogen recycling, grasses, legume, N mineralization.

\section{NTRODUÇÃO}

O plantio direto, sistema conservacionista de manejo, que mantém os resíduos culturais na superfície dosolo, constitui uma importantetécnica para a manutenção e recuperação da capacidade produtiva de sol os manejados convencionalmente e deáreas degradadas. A eficácia da semeadura direta está relacionada, dentre outros fatores, com a quantidade equalidade deresíduos produzidos pelas plantas de cobertura e com a persistência destes sobre o solo (Gonçalves \& Ceretta, 1999). Com isso deverá haver a manutenção e, ou, incremento dos teores de matéria orgânica, melhorando a disponibilidade de nutrientes para as culturas subseqüentes (Rei coscky \& F orcella, 1998), além de outros benefícios, tais como: a redução da erosão do solo (Carval ho et al., 1990), a mel horia nos atributos físi cos dos sol os (Carpenedo \& Miel niczuck, 1990), a elevação dos teores de N total (Souza \& Mello, 2000), o acúmulo de $\mathrm{P}$ (Muzilli, 1981) e o aumento da disponibilidade de P, K, Ca e Mg (Calegari et al., 1992) superficialmente no solo.

O manejo dos resíduos culturais, em superfície ou incorporação no solo, resulta em diferentes vel ocidades de decomposição. Todavia, não existe consenso na literatura com rel ação ao mel hor método para avaliação desta decomposição, sendo a concentração de $\mathrm{N}$ e as relações $\mathrm{C} / \mathrm{N}$ e lignina/N sugeridas por alguns autores (Mellilo et al., 1982; Berg, 1986). Outros autores avaliam esta decomposição por meio da incubação de material vegetal com solo, em laboratório ou no campo, sendo esta taxa estimada pela perda de peso decorrente da liberação de carbono na forma de $\mathrm{CO}_{2}$ ( $\mathrm{Holtz}$, 1995; Silva et al., 1997; Schunke, 1998).

Estudando a velocidade de decomposição da pal hada de milheto e sorgo, bem como o acúmulo de nutrientes na fitomassa esua mineralização, M oraes (2001) observou que a taxa média de decomposição da palhada é maior nos primeiros 42 dias e que a mineralização dos nutrientes é mais acentuada nos primeiros 63 dias após a dessecação e rolagem dos resíduos. Bertol et al. (1998) verificaram que, após 180 dias, a aveia-preta apresentou uma diminuição de $80 \%$ e o milho de $64 \%$ da massa seca remanescente quando incorporada ao solo.

Silva et al. (1997) avaliaram a taxa de decomposição de crotalária, guandu, mucuna-preta e braquiária em sol o sob cerrado nativo e solos descobertos. Obtiveram taxas de decomposição de 61,3, $61,9,65,6$ e 78,9 \%, respectivamente, decorridos 60 dias após a implantação das bolsas de decomposição.

Borkert et al. (2003) relacionaram a produção de matéria seca, acúmulo e liberação de nutrientes da biomassa de aveia-preta, guandu, mucuna-preta, tremoço e ervilhaca. Os autores observaram que o rendimento de matéria seca (MS) variou de 5 a 10; 2 a 10; 1,7 a 8,6; 7 a 13 e 6,5 Mg ha-1; que o acúmulo de N variou de 37 a 138; 43 a 288; 66 a 280; 186 a 492 e $246 \mathrm{~kg} \mathrm{ha}^{-1}$ de $\mathrm{N}$, respectivamente, para as culturas estudadas. Aita et al. (2001), em estudo semel hante, constataram que a produção de MS de ervilhaca comum, ervilha forrageira, chicharo, tremoço, aveia-preta e pousio foi de 2,52; 2,75; 3,05; 5,23; 4,42 e 1,20 Mg ha-1, com relação $\mathrm{C} / \mathrm{N}$ de 10,5; 13,$1 ; 12,4 ; 15,4 ; 34,9$ e 17,6 , respectivamente. Spagnolo et al. (2002) observaram relação $\mathrm{C} / \mathrm{N}$ de 14; 19; 15 e 16 e produção de MS de 2,83; 5,01; 4,29 e 1,26 Mg ha-1, para feijão de porco, guandu-anão, mucuna-preta e soja preta, respectivamente.

Guimarães (2000), avaliando o efeito de rotações de culturas no verão (milho e soja), com uso da área no inverno (feijão, milheto, mucuna, braquiária e pousio), observou que a produção de MS das coberturas de inverno foi de 7.199, 7.296, 7.143, 6.912 e $7.479 \mathrm{~kg} \mathrm{ha}^{-1}$, e o acúmulo de $\mathrm{N}$ nesse material foi de $58,6,70,6,64,6,62,4$ e60,3 kg ha-1, respectivamente. 
Este trabalho teve como objetivo avaliar o rendimento de matéria seca ea taxa de decomposição e de liberação de $\mathrm{N}$ de resíduos culturais provenientes de plantas de cobertura em solos de cerrado, em U beraba (MG).

\section{MATERIAL E MÉTODOS}

O trabal ho foi desenvolvido durante o período de setembro de 2000 a março de 2002, na área experimental do Centro Federal de Educação Tecnológica de U beraba (CEFET), no município de U beraba, MG (19 o 39 ' 19 " S, 47 57 ' 27 " W, a cerca de 795 m dealtitude). A precipitação média anual é de $1.600 \mathrm{~mm}$; a temperatura média anual é de $22,6{ }^{\circ} \mathrm{C}$ e a umidade relativa do ar média é de $68 \%$. O clima é classificado como Aw, tropical quente, segundo a classificação de Köppen, apresentando inverno frio e seco. O solo da área experimental foi classificado como L atossolo Vermel ho distrófico de acordo com Embrapa (1999). A presenta as seguintes características na camada arável $(0-20 \mathrm{~cm})$; $180 \mathrm{~g} \mathrm{~kg}^{-1}$ de argila, $\mathrm{pH} \mathrm{H}_{2} \mathrm{O}(1: 2,5) 6,3 ; 17 \mathrm{mg} \mathrm{dm}^{-3}$ de $\mathrm{P} ; 96 \mathrm{mg} \mathrm{dm}^{-3}$ de $\mathrm{K} ; 1,9 \mathrm{cmol}_{\mathrm{c}} \mathrm{dm}^{-3}$ de $\mathrm{Ca}^{2+}$; $0,6 \mathrm{cmol}_{\mathrm{c}} \mathrm{dm}^{-3}$ de $\mathrm{Mg}^{2+} ; 2,0 \mathrm{cmol}_{c} \mathrm{dm}^{-3}$ de $\mathrm{H}+\mathrm{Al}$ e $16 \mathrm{~g} \mathrm{dm}^{-3}$ de matéria orgânica. As análises foram realizadas segundo Embrapa (1997).

O experimento foi instalado em agosto de 2000, sendo utilizadas as seguintes plantas de cobertura: milheto (Pennisetum americanum sin. tiphoydes), braquiária (Brachiaria brizantha), sorgo forrageiro (Sorghum bicolor L. Moench), guandu (Cajanus cajan (L.) Millsp), crotalária juncea (Crotalarea juncea) e aveia-preta (Avena strigosa Schreb), além de ser também utilizada uma área em pousio e uma área testemunha (plantio convencional). O delineamento experimental adotado foi o de blocos ao acaso, com quatro repetições, num total de 32 parcelas de $40 \mathrm{~m}^{2}(4 \times 10 \mathrm{~m})$. Na área de pousio, foi feita a identificação das plantas invasoras, sendo constatada a presença de espécies de diversas famílias (Quadro 1), com predomínio de gramíneas.

Aos 110 dias do plantio (DAP) das coberturas, para aval iação da MS produzida, fez-sea amostragem em 2 pontos ao acaso em cada parcela, com o auxílio de um quadrado metálico de $1 \mathrm{~m}^{2}$ de área, Iançado aleatoriamente. Coletou-se todo material contido na área delimitada por este quadrado. O material vegetal foi levado aolaboratório, colocado em estufa de circulação forçada a $65 \stackrel{\circ}{ } \mathrm{C}$, por $72 \mathrm{~h}$, e, posteriormente, pesado. Após esta amostragem, as plantas de cobertura foram dessecadas, aplicandose $1.440 \mathrm{~g} \mathrm{ha}^{-1}$ de glifosato $+600 \mathrm{~g} \mathrm{ha}^{-1}$ de Paraquat.

Plantou-se o milho híbrido duplo AG 1051 da Agroceres com seis sementes por metro e $90 \mathrm{~cm}$ de espaçamento entre linhas e a soja MG/BR-46 Conquista de semi-tardio com 15 sementes por metro e espaçamento de $45 \mathrm{~cm}$ entrelinhas. Foi utilizada uma plantadora $\mathrm{PST}_{2}$ da Tatu. Para adubação de plantio de milho, utilizaram-se $32 \mathrm{~kg} \mathrm{ha}^{-1}$ de $\mathrm{N}$, $80 \mathrm{~kg} \mathrm{ha}^{-1}$ de $\mathrm{P}_{2} \mathrm{O}_{5}, 80 \mathrm{~kg} \mathrm{ha}^{-1} \mathrm{~K}_{2} \mathrm{O}$ e $1,2 \mathrm{~kg} \mathrm{ha}^{-1}$ de $\mathrm{Zn}$. Em cobertura, aplicaram-se $90 \mathrm{~kg} \mathrm{ha}^{-1}$ de $\mathrm{N}$ na forma de uréia 10 dias após a emergência e mais $20 \mathrm{~kg} \mathrm{ha}^{-1}$ de $\mathrm{N}$ na forma de sulfato de amônia 25 dias após a emergência, nos dois anos agrícolas avaliados. Para soja, foram utilizados $8 \mathrm{~kg} \mathrm{ha}^{-1} \mathrm{de}$ $\mathrm{N}, 80 \mathrm{~kg} \mathrm{ha}^{-1}$ de $\mathrm{P}_{2} \mathrm{O}_{5}, 80 \mathrm{~kg} \mathrm{ha}^{-1} \mathrm{~K}_{2} \mathrm{O}$ e $1,2 \mathrm{~kg} \mathrm{ha}^{-1}$ de $\mathrm{Zn}$, sem inoculação. Considerando os teores de Ca e de Mg verificados, não foi realizada calagem na área. F oram feitos o tratamento das sementes e o controle de pragas, doenças e plantas daninhas necessários durante o cicl o das culturas.

Quadro 1. Plantas identificadas nas áreas sob pousio, ano agrícola 2000/2001

\begin{tabular}{lll}
\hline Família & Nome científico & Nome comum \\
\hline Solanaceae & Nicandra physaloides & J oá-de-capote \\
Portulacaceae & Portulaca ol eracea L. & Beldroega \\
Amaranthaceae & Amaranthus spp. & Caruru \\
Compositae & Bidens pilosa & Picão-preto \\
Gramineae & Cenchrus echinatus L. & Timbete \\
Gramineae & Digitaria insularis & Capim-amargoso \\
Gramineae & Brachiaria plantaginea & Capim-marmelada \\
Compositae & Acanthospermum hispidum & Carrapicho-de-carneiro \\
Gramineae & Rhynchelytrum repens & Capim-favorito \\
Labiatae & Hyptis suaveolens L. & Cheirosa \\
Rubiaceae & Richardia brasiliensis & Poaia \\
Solanaceae & Solanum americanum & Maria-pretinha \\
Cyperaceae & Cyperus esculentum & Tiririca \\
Gramineae & Brachiaria decumbens & Braquiária decumbens \\
Gramineae & Eleusineindica & Capim-pé-de-galinha \\
Gramineae & Panicum maximum & Capim-colonião \\
\hline
\end{tabular}


Logo após a colheita do milho e da soja, ao final de março de 2001, foram semeadas novamente as coberturas vegetais, nos mesmos locais, sendo estas também dessecadas aos 110 DAP. O plantio do milho e da soja, no ano agrícola 2001/2002, foi realizado em novembro/2001, sendo as culturas rotacionadas, ocupando posi ções distintas do experimento anterior nas subparcelas.

No material seco coletado aos 110 DAP, foi feita a análise química de: $\mathrm{N}$ - total, utilizando o método de destilação de Kjehldal (Hildebrand, 1976) e Corgânico, pel o método de Walk ley eBlack modificado (Tedesco et al., 1985).

Para avaliar a taxa de decomposição e liberação de nutrientes, foi empregado o método das bolsas de decomposição (Santos \& Whilford, 1981; Silva et al., 1997; Schunke, 1998; Espíndola et al., 1998). As bolsas de decomposição foram confeccionadas a partir de material plástico (nylon com malha de $2 \mathrm{~mm}$ de abertura), apresentando dimensões de $0,04 \mathrm{~m}^{2}(20 \times 20 \mathrm{~cm})$. Em cada bol sa foram colocadas $10 \mathrm{~g}$ de parte aérea das plantas de cobertura (secas em estufa, a $65^{\circ} \mathrm{C}$ até peso constante). Foram distribuídas vinte bolsas na superfície do solo em cada parcela. Em cada parcela, foram realizadas cinco amostragens: a primeira, 42 dias após a instalação, e as demais, em intervalos regulares de 56 dias (110, 152, 208, 264 e 320 dias após o plantio). Em cada amostragem, col etaram-se quatro bolsas por tratamento. Após a coleta das amostras, o material foi lavado em água corrente em peneira de malha de $0,053 \mathrm{~mm}$, seco em estufa de circulação forçada de ar (65 ㄷ até peso constante) e, posteriormente, moído.

No material vegetal, determinou-seoC-orgânico, pel o método de Walkley eBlack modificado (Tedesco et al., 1985), e o N-total, pelo método de Kjeldahl (Hildebrand, 1976).

Para descrever a decomposição dos resíduos vegetais e a liberação de $\mathrm{N}$, aplicou-se um modelo matemático exponencial, descrito por Thomas \& Asakawa (1993) eutilizado por Rezendeet al . (1999):

$$
P=P_{0} . \exp (-k . t),
$$

em que P é a fração do resíduo inicial existente no tempot,

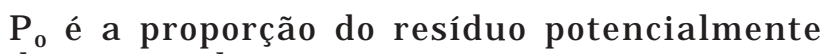
decomponível e

k é a constante de decomposição do resíduo.

Com o valor de k, calculou-se o tempo de meiavida $\left(T_{1 / 2}\right)$. Para cada espécie foram ajustadas equações de regressão, relacionando a quantidade média de nutriente reciclada $(\mathrm{N})$ em razão da quantidade de matéria seca produzida para cada cultura, utilizando o Software SigmaPlot, versão 2000.
Para subsidiar a interpretação dos resultados, foram apresentados os dados climáticos médios mensais de temperatura epreci pitação pluviométrica (Figura 1), extraídos do conjunto de dados pertencentes ao acervo da Estação M eteorológica da EPAMIG, localizada na Fazenda Experimental Getúlio Vargas, em U beraba (MG).

As análises estatísticas foram realizadas com o auxílio do sistema para análises estatísticas e genéticas (SAEG), versão 5,0 (Euclides, 1983). As avaliações constaram de análise de variância, aplicando o teste F para significância. Quando este foi significativo, compararam-seas médias pel oteste deTukey $(p<0,05)$.

\section{RESULTADOS E DISCUSSÃO}

\section{Rendimento MS, acúmulo de $\mathrm{N}$ e relação $\mathrm{C} / \mathrm{N}$ das plantas de cobertura}

$\mathrm{O}$ rendimento de $\mathrm{MS}$, a quantidade de $\mathrm{N}$ acumulado no tecido vegetal da parte aérea e a relação $\mathrm{C} / \mathrm{N}$ das coberturas de solo analisadas apresentaram comportamentos diferenciados nas duas épocas de plantio avaliadas (Quadro 2). No ano agrícola 2000/01, o plantio das coberturas foi realizado no início do período das chuvas e, no segundo ano (2001/02), as coberturas avaliadas foram plantadas após a retirada das culturas anuais, na primeira quinzena de abril, período em que se observou a diminuição das chuvas (Figura 1). Verificou-se que, no ano agrícola, as condições adversas, decorrentes das baixas taxas de precipitação, não foram suficientes para impedir a germinação das sementes e desenvolvimento das coberturas.

No primeiro ano agrícola estudado 2000/01, o milheto foi a planta que apresentou a maior produção de MS e o guandu a menor produção (Quadro 2). As demais coberturas apresentaram rendimentos intermediários com produção de MS variando de 2,00 a 7,00 $\mathrm{Mg} \mathrm{ha}^{-1}$.

Dentre todas as coberturas, as gramíneas foram as que apresentaram a maior produção de MS (Quadro 2). Os valores obtidos para o mil heto foram próximos aos obtidos por Chaves (1997), 10,3 Mg ha-1; Moraes (2001), 9,65 Mg ha-1; Oliveira (2001), $8,0 \mathrm{Mg} \mathrm{ha}^{-1}$, em condição de cerrado, e por Cal egari et al. (1993), 9,9 Mg ha-1, no Paraná, em diferentes regiões agrícolas. Para o sorgo, obteve-se uma produção de matéria seca abaixo dos valores encontrados por Moraes (2001) e Oliveira (2001), $10,71,15,48 \mathrm{Mg} \mathrm{ha}^{-1}$, respectivamente. Os valores de matéria seca para aveia-preta foram inferiores aos 4,41 Mg ha-1, verificados por Aita et al. (2001), e aos 4,91 Mg ha-1, observados por Heinrichs et al. (2001). Esta diferença de produtividade mostrouse relacionada com o clima mais quente do que o ideal para a aveia-preta. 
Quadro 2. Produção de matéria seca (MS), $\mathbf{N}$ acumulado e relação $\mathrm{C} / \mathrm{N}$ das plantas de cobertura, nos anos agrícolas de 2000/01 a 2001/02

\begin{tabular}{|c|c|c|c|c|c|c|}
\hline \multirow{2}{*}{ Planta de cobertura } & \multicolumn{3}{|c|}{ 2000/01 } & \multicolumn{3}{|c|}{ 2001/02 } \\
\hline & MS & $\mathrm{N}$ acumulado & Relação C/N & MS & N acumulado & Relação $\mathbf{C} / \mathbf{N}$ \\
\hline & $\mathrm{Mg} \mathrm{ha}^{-1}$ & $\mathrm{~kg} \mathrm{ha}^{-1}$ & & $\mathrm{Mg} \mathrm{ha}^{-1}$ & $\mathrm{~kg} \mathrm{ha}^{-1}$ & \\
\hline Pousio & $2,1 d^{(1)}$ & $46,7 d$ & $9,5^{(2)}$ & $3,8 a^{(1)}$ & $\begin{array}{l}57,2 \mathrm{~b} \\
55,8 \mathrm{~b}\end{array}$ & $25,3^{(2)}$ \\
\hline $\begin{array}{l}\text { Milheto } \\
\text { Sorqo }\end{array}$ & $\begin{array}{r}10,3 \mathrm{a} \\
7,1 \mathrm{~b}\end{array}$ & $\begin{array}{r}165,6 \text { a } \\
84,1 \mathrm{c}\end{array}$ & $\begin{array}{l}21,7 \\
24,3\end{array}$ & $\begin{array}{l}3,6 \mathrm{a} \\
4,0 \mathrm{a}\end{array}$ & $\begin{array}{l}55,8 \mathrm{~b} \\
45,0 \mathrm{c}\end{array}$ & $\begin{array}{l}25,3 \\
34,6\end{array}$ \\
\hline $\begin{array}{l}\text { Sorgo } \\
\text { Crotalária }\end{array}$ & $\begin{array}{l}7,1 \mathrm{~b} \\
3,9 \mathrm{~cd}\end{array}$ & $\begin{array}{r}84,1 \mathrm{c} \\
118,1 \mathrm{~b}\end{array}$ & $\begin{array}{l}24,3 \\
11,5\end{array}$ & $\begin{array}{l}4,0 \mathrm{a} \\
3,7 \mathrm{a}\end{array}$ & $\begin{array}{l}45,0 \mathrm{c} \\
76,4 \mathrm{a}\end{array}$ & $\begin{array}{l}34,0 \\
18,1\end{array}$ \\
\hline Aveia & $2,4 \mathrm{~d}$ & $29,2 \mathrm{e}$ & 30,6 & $3,4 a b$ & $46,0 \mathrm{c}$ & 28,3 \\
\hline Guandu & $1,6 \mathrm{~d}$ & $51,3 \mathrm{~d}$ & 11,3 & $2,7 \mathrm{bc}$ & $62,4 a b$ & 16,6 \\
\hline Braquiária & $6,0 \mathrm{bc}$ & $130,8 \mathrm{~b}$ & 16,1 & $2,1 \mathrm{c}$ & $41,6 \mathrm{c}$ & 19,6 \\
\hline C.V. (\%) & 20,7 & & & 10,9 & & \\
\hline
\end{tabular}

(1) Médias seguidas de mesma letra, na coluna, não diferem entre si a $5 \%$ (Tukey). ${ }^{(2)}$ Não foi feita a análise estatística da relação C/ $\mathrm{N}$, porque o teor de C foi avaliado a partir de uma amostra composta, constituída pelas quatro repetições.

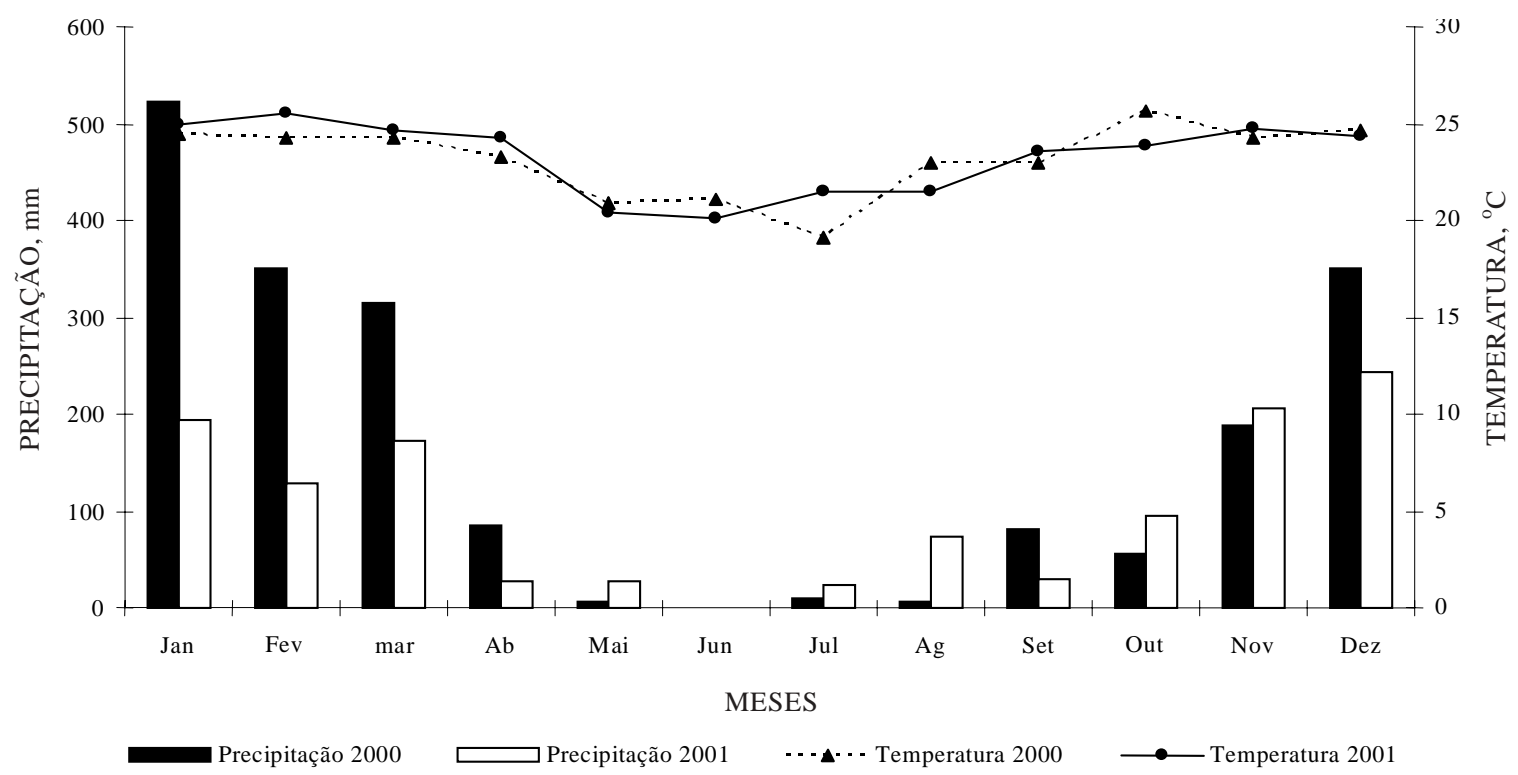

Figura 1. Temperatura e precipitação pluviométrica média obtida junto à Estação Meteorológica da EPAMIG em Uberaba (MG).

Quanto às leguminosas, de maneira geral, os valores obtidos para MS foram relativamente baixos (Quadro 2). Spagnolo et al. (2002) obtiveram produção de MS de 5,01 $\mathrm{Mg} \mathrm{ha}^{-1}$ para o guandu. Em áreas sob pousio, Aita et al. (2001) verificaram valores de produção de MS de 1,19 Mg ha-1, valor inferior aos encontrados neste trabal ho.

Em 2001, as produções de MS foram inferiores às verificadas no primeiro ano agrícola (Quadro 2), fato atribuídoàs condições climáticas adversas a que as plantas de cobertura foram submetidas, com destaque para a baixa precipitação pluviométrica (1.200 mm) (Figura 1), abaixo do normal na região. As menores produções de MS foram do guandu e braquiária (Quadro 2). Apesar da redução da produção de matéria seca, pode-se destacar o aumento da produção de resíduos vegetais da aveiapreta $\left(3,36 \mathrm{Mg} \mathrm{ha}^{-1}\right)$, evidenciando ser esta planta mais adaptada às condições hídricas mais adversas. Comportamento similar foi verificado para a área de pousio, na qual a produção de matéria seca foi de 3,79 Mg ha-1.

Para as leguminosas, guandu e crotalária, foram obtidos val ores de produção de 2,66 e 3,69 $\mathrm{Mg} \mathrm{ha}^{-1}$, respectivamente. Em comparação ao primeiro ano de cultivo, verificou-se um aumento na produção de matéria seca para o guandu e manutenção do mesmo rendimento de matéria seca para a crotalária. A superioridade das leguminosas deveu-se ao sistema radicular pivotante, mais profundo, quando comparado ao das gramíneas, o que contribuiu para maior absorção de água. 
Os maiores valores de $\mathrm{N}$ acumulado, no ano agrícola 2000/01, foram do milheto (Quadro 2), a cobertura que produziu a maior quantidade de resíduos vegetais. Moraes (2001), em solos de cerrado, encontrou valores semelhantes: $9,65 \mathrm{Mg} \mathrm{ha}^{-1}$ de MS e $126,7 \mathrm{~kg} \mathrm{ha}^{-1}$ de N. Dentre as demais gramíneas, a braquiária foi a que apresentou os maiores val ores de $\mathrm{N}$ acumulado, seguida pel o sorgo e pela aveia-preta. Quanto às leguminosas, a maior quantidade de $\mathrm{N}$ acumulado pode ser explicada pela fixação biológica de $\mathrm{N}_{2}$. Para o primei roano agrícola, o teor de $\mathrm{N}$ acumulado na crotalária foi mais que o dobro do verificado no guandu. No segundo ano, não foram observadas diferenças no teor de $\mathrm{N}$ para as leguminosas, verificando-se que estas foram as que apresentaram o maior acúmulo de $\mathrm{N}$ neste período. $\mathrm{Na}$ área de pousio, a quantidadeacumulada deN foi de 46,69 kg ha-1. Aita et al. (2001) observaram para áreas de pousio valores de $\mathrm{N}$ acumulado da ordem de 20,5 $\mathrm{kg} \mathrm{ha}^{-1} \mathrm{em} \mathrm{1,19} \mathrm{Mg} \mathrm{ha}^{-1}$ de palha.

Quanto à relação $\mathrm{C} / \mathrm{N}$ nas plantas de cobertura (Quadro 2), observaram-se variações entre os anos agrícolas, sendo verificado o aumento dos valores no ano agrícola 2001/02 para todas as plantas de cobertura, com exceção da aveia-preta. U ma possível explicação para o aumento da relação $\mathrm{C} / \mathrm{N}$, no ano agrícola de 2001, pode estar relacionada com as condições climáticas que podem ter desfavorecido a absorção de $\mathrm{N}$ pelas gramíneas e a fixação biológica nas leguminosas. I ndependentemente do ano agrícola, as leguminosas, graças à fixação biológica de $\mathrm{N}_{2}$, foram as que apresentaram as menores relações $\mathrm{C} / \mathrm{N}$.

\section{Decomposição de resíduos}

Em todos os tratamentos, a cinética do processo de decomposição dos resíduos culturais foi similar, decrescendo exponencialmente com o tempo (Figura 1). No ano agrícola 2000/01, pousio e braquiária apresentaram comportamento similar e as maiores taxas de decomposição de MS. Nas parcelas com milho e soja, foram decompostos 55 e $59 \%$ dos restos culturais nos primeiros 42 dias, restando 13 e $11 \%$ da massa seca, respectivamente, aos 320 dias.

Para a crotalária e a aveia-preta, foram verificadas taxas iniciais de decomposição similares, 43,8 e $43,1 \%$, respectivamente, nos primeiros 42 dias. Aos 320 dias, porém, a taxa de decomposi ção da crotalária (68 \%) foi menor do que da aveia-preta (74 \%) (Figura 1). Silva et al. (1997) também observaram que as leguminosas decompõem mais lentamente que as gramíneas, em condições de solo descoberto no cerrado, mesmo quando a relação $\mathrm{C} / \mathrm{N}$ das gramíneas é maior como neste estudo (Quadro 3).

Quanto ao tempo de meia-vida ( $\left.T^{1 / 2}\right)$ para decomposição dos resíduos, observou-se que metade dos resíduos vegetais provenientes da área de pousio e da área de braquiária havia se decomposto, respectivamente, aos 65 dias e aos 52 dias. Este baixo tempo de meia-vida deveu-se à baixa relação $\mathrm{C} / \mathrm{N}$ destes materiais (Quadro 2). Quanto à influência das culturas de milho e soja nas taxas de decomposição (Quadro 3 e Figura 1), observou-se influência semelhante no final do primeiro ano

Quadro 3. Constante de decomposição, tempo de meia-vida ( $T^{1 / 2}$ ) da massa seca e $\mathbf{N}$ remanescente contido nas coberturas no ano agrícola 2000/01, para as culturas de milho e soja

\begin{tabular}{|c|c|c|c|c|c|c|}
\hline \multirow{2}{*}{ Planta de cobertura } & \multicolumn{3}{|c|}{ Decomposição dos resíduos } & \multicolumn{3}{|c|}{ Mineralização de $\mathbf{N}$} \\
\hline & $\mathbf{k}$ & $\mathbf{T}^{1 / 2}$ & $\mathbf{r}^{2}$ & $\mathbf{k}$ & $\mathbf{T}^{1 / 2}$ & $\mathbf{r}^{2}$ \\
\hline & $\mathrm{g} \mathrm{g}^{-1}$ & dia & & $\mathrm{g} \mathrm{g}^{-1}$ & dia & \\
\hline & \multicolumn{6}{|c|}{ Cultura de milho } \\
\hline $\begin{array}{l}\text { Pousio } \\
\text { Milheto } \\
\text { Sorgo } \\
\text { Crotalária } \\
\text { Aveia } \\
\text { Guandu } \\
\text { Braquiária }\end{array}$ & $\begin{array}{l}0,0107 \\
0,0053 \\
0,0067 \\
0,0067 \\
0,0064 \\
0,0062 \\
0,0132\end{array}$ & $\begin{array}{r}65 \\
131 \\
103 \\
103 \\
108 \\
112 \\
52\end{array}$ & $\begin{array}{l}0,98^{* *} \\
0,97^{* *} \\
0,97^{* *} \\
0,92^{*} \\
0,95^{*} \\
0,99^{* *} \\
0,96 *\end{array}$ & $\begin{array}{l}0,0148 \\
0,0069 \\
0,0049 \\
0,0320 \\
0,0049 \\
0,0146 \\
0,0147\end{array}$ & $\begin{array}{r}47 \\
100 \\
141 \\
22 \\
141 \\
47 \\
47\end{array}$ & $\begin{array}{l}0,97^{*} \\
0,91^{*} \\
0,87^{* * *} \\
0,95^{* * *} \\
0,91^{*} \\
0,95^{*} \\
0,96^{*}\end{array}$ \\
\hline Braquiária & \multicolumn{6}{|c|}{ Cultura de soja } \\
\hline $\begin{array}{l}\text { Pousio } \\
\text { Milheto } \\
\text { Sorgo } \\
\text { Crotalária } \\
\text { Aveia } \\
\text { Guandu } \\
\text { Braquiária }\end{array}$ & $\begin{array}{l}0,0128 \\
0,0053 \\
0,0053 \\
0,0074 \\
0,0062 \\
0,0061 \\
0,0115\end{array}$ & $\begin{array}{r}54 \\
131 \\
131 \\
94 \\
112 \\
114 \\
60\end{array}$ & $\begin{array}{l}0,95^{*} \\
0,96^{* *} \\
0,96^{* *} \\
0,97^{* *} \\
0,96 * * \\
0,99^{* *} \\
0,95^{*}\end{array}$ & $\begin{array}{l}0,0187 \\
0,0070 \\
0,0041 \\
0,0275 \\
0,0041 \\
0,0144 \\
0,0115\end{array}$ & $\begin{array}{r}37 \\
99 \\
169 \\
25 \\
169 \\
48 \\
60\end{array}$ & $\begin{array}{l}0,95^{*} \\
0,92^{*} \\
0,82^{* * *} \\
0,94^{* * *} \\
0,82^{* * *} \\
0,95^{* * *} \\
0,95^{* * *}\end{array}$ \\
\hline
\end{tabular}

${ }^{(1)} \mathrm{k}=$ Constante de decomposição; T1/2 = Meia-vida.

*, ** e***: Significativos a 1, 5 e $10 \%$. 
agrícola. As variações nas condições climáticas nos anos agrícolas estudados pouco influenciaram a vel ocidade de decomposição dos resíduos culturais. Dentre todas as coberturas, a aveia-preta foi a que apresentou o maior $\mathrm{T}^{1} / 2, \mathrm{o}$ que pode ser explicado pela sua maior relação C/N $(30,6)$.

Em 2001/02, a taxa de decomposição foi mais lenta para todas as sete coberturas, quando comparadas à do primeiro ano. Esta diferença fica evidente quando se compara $\mathrm{T}^{1} / 2$ das culturas, mai or no segundo ano (Quadro 4). Dentre as coberturas, a menor diminuição na vel ocidade de decomposição dos resíduos foi para a braquiária. No segundo ano, a relação $\mathrm{C} / \mathrm{N}$, em todas as culturas, aumentou em relação ao primeiro ano, com exceção da aveia-preta (sem diferença). Também nesse ano agrícola, não foram verificadas diferenças nas taxas de decomposição das coberturas para as culturas de milho ou soja. Ou seja, a cultura implantada não influenciou as taxas de decomposição dos resíduos.

O guandu ea braquiária foram as coberturas que apresentaram os menores T11/2 (Quadro 4). Para as coberturas milheto, braquiária, sorgo, crotalária e guandu, foram observadas taxas de decomposição idênticas nos primeiros 42 dias após plantio, tendo o milheto, sorgo e crotalária mantido a mesma proporção de material remanescente ao final do experimento.

Comparando a taxa de decomposição obtida nos dois anos de experimentação, acredita-se que as diferenças observadas sejam devidas às condições de temperatura, precipitação e umidade. No primeiro ano, a precipitação foi de $1.970 \mathrm{~mm}$ (Figura 1), tendo a dessecação das plantas de cobertura e a introdução das bol sas de decomposição ocorrido na época das águas, enquanto, no segundo ano, essas práticas foram realizadas no início do período secoe demenores temperaturas. Além disto, neste ano, foram verificados menores índices de precipitação anual (1.224 mm).

Com relação à taxa de decomposição das coberturas nas parcelas de milho e soja, observouse que a decomposição dos restos culturais das coberturas foi idêntica nas cinco primeiras avaliações. A partir dos 152 dias após plantio, verificaram-se diferenças na taxa de decomposição nas diferentes culturas. Observou-se que, nas parcelas de soja, a decomposição foi maior 152 e 208 dias após o plantio, e inferior 320 dias após o plantio. Este comportamento demonstra que as plantas de cobertura em área de plantio de soja apresentaram taxa de decomposição inicial mais rápida. Para o milho, as taxas foram mais rápidas, restando apenas $26,3 \%$ dos resíduos vegetais.

\section{Mineralização de N}

No quadro 2, são apresentados os valores de $\mathrm{N}$ dos materiais avaliados durante o período de experimentação. Em 2000/01, observou-se que as plantas de cobertura apresentaram acúmulo de $\mathrm{N}$ no tecido vegetal, com destaque para mil heto, sorgo e braquiária e crotalária.

Quadro 4. Constante de decomposição, tempo de meia-vida $\left(T^{1 / 2}\right)$ da massa seca e do $N$ remanescente contido nas coberturas no ano agrícola 2001/02, para as cultura de milho e soja

\begin{tabular}{|c|c|c|c|c|c|c|}
\hline \multirow{2}{*}{ Planta de cobertura } & \multicolumn{3}{|c|}{ Decomposição dos resíduos } & \multicolumn{3}{|c|}{ Mineralização de N } \\
\hline & $\mathbf{k}$ & $\mathbf{T}^{1 / 2}$ & $\mathbf{r}^{2}$ & $\mathbf{k}$ & $\mathbf{T}^{1 / 2}$ & $\mathbf{r}^{2}$ \\
\hline & $\mathrm{g} \mathrm{g}^{-1}$ & dia & & $\mathrm{g} \mathrm{g}^{-1}$ & dia & \\
\hline & \multicolumn{6}{|c|}{ Cultura de milho } \\
\hline $\begin{array}{l}\text { Pousio } \\
\text { Milheto } \\
\text { Sorgo } \\
\text { Crotalária } \\
\text { Aveia } \\
\text { Guandu } \\
\text { Braquiária }\end{array}$ & $\begin{array}{l}0,0047 \\
0,0062 \\
0,0059 \\
0,0046 \\
0,0052 \\
0,0063 \\
0,0090\end{array}$ & $\begin{array}{r}147 \\
112 \\
117 \\
151 \\
133 \\
110 \\
77\end{array}$ & $\begin{array}{l}0,99 * * \\
0,98 * * \\
0,99 * * \\
0,97 * * \\
0,99 * * \\
0,99 * * \\
0,99 * *\end{array}$ & $\begin{array}{l}0,0073 \\
0,0081 \\
0,0072 \\
0,0102 \\
0,0056 \\
0,0102 \\
0,0115\end{array}$ & $\begin{array}{r}95 \\
86 \\
96 \\
68 \\
124 \\
68 \\
60\end{array}$ & $\begin{array}{l}0,95^{* *} \\
0,95^{* *} \\
0,96^{* *} \\
0,94^{*} \\
0,97^{* *} \\
0,99^{* *} \\
0,96^{*}\end{array}$ \\
\hline Braquiária & \multicolumn{6}{|c|}{ Cultura de soja } \\
\hline $\begin{array}{l}\text { Pousio } \\
\text { Milheto } \\
\text { Sorgo } \\
\text { Crotalária } \\
\text { Aveia } \\
\text { Guandu } \\
\text { Braquiária }\end{array}$ & $\begin{array}{l}0,0050 \\
0,0058 \\
0,0059 \\
0,0056 \\
0,0054 \\
0,0075 \\
0,0089\end{array}$ & $\begin{array}{r}139 \\
119 \\
118 \\
124 \\
128 \\
92 \\
78\end{array}$ & $\begin{array}{l}0,98 * * \\
0,97 * * \\
0,99 * * \\
0,99 * * \\
0,98 * * \\
0,99 * * * \\
0,99 * * *\end{array}$ & $\begin{array}{l}0,0073 \\
0,0077 \\
0,0069 \\
0,0108 \\
0,0057 \\
0,0108 \\
0,0073\end{array}$ & $\begin{array}{r}95 \\
90 \\
100 \\
64 \\
122 \\
64 \\
95\end{array}$ & $\begin{array}{l}0,98^{* *} \\
0,94^{*} \\
0,95^{*} \\
0,97^{* *} \\
0,98^{* *} \\
0,99^{* *} \\
0,99 * *\end{array}$ \\
\hline
\end{tabular}

(1) $\mathrm{k}=$ Constante de decomposição; T1/2 = Meia-vida.

$*, * *$ e***: Significativos a 1,5 e $10 \%$. 
Houve grande variabilidade do $\mathrm{T}^{1 / 2}$ do $\mathrm{N}$ remanescente (Quadros 3 e 4). A aveia-preta e o sorgo foram as coberturas que mais tempo levaram para atingir a meia-vida. Na parcela de soja, este tempo foi de 169 dias e, nas de milho, 141 dias. A crotálaria foi a cobertura que apresentou a mais rápida liberação de $\mathrm{N}$, atingindo $\mathrm{T}^{1} / 2$ vida aos 22 dias nas parcelas de soja e 25 dias nas de milho. 0 guandu, apesar de ter apresentado a menor produção de matéria seca, quando comparado ao pousio e a aveia-preta, foi o que acumulou maiores quantidades de $\mathrm{N}$.

Quanto ao acúmulo de $\mathrm{N}$, destacaram-se as leguminosas crotalária e guandu. O menor $\mathrm{T}^{1} 1 / 2$ vida foi observado para a aveia-preta, com 124 e 122 dias, nas parcelas de soja e milho, respectivamente (Quadros 3 e 4). A despeito da menor taxa de liberação de N, esta é a cobertura que mais protege o solo.

No segundo ano, a braquiária foi a cobertura que apresentou a maior taxa de decomposição nas parcelas de milho, atingindo $T^{1} 1 / 2$ aos 60 dias e a crotalária, nas parcelas de soja (64 dias) (Quadro 4). Associando a taxa de decomposição das plantas de cobertura, rendimento de MS eliberação de N, esses materiais poderão ser manejados de acordo com as necessidades das culturas em sucessão, pois o N liberado em grandes quantidades, dependendo da época do ano, pode ser perdido por lixiviação e, ou, imobilização.

A maior mineralização de $\mathrm{N}$ ocorreu nos primeiros 42 dias para todas as culturas. Guandu
$(67,5 \%)$, milheto $(64,2 \%)$ e sorgo $(62,2 \%)$ foram os resíduos que mais mineralizaram, enquanto pousio $(44,6 \%)$ e braquiária $(40,8 \%)$ os que menos mineralizaram. Em valores absolutos, a braquiária, o milheto ea crotalária foram as que mais liberaram N (Quadro 5). A alta taxa de decomposição dos resíduos, nos primei ros 42 dias, está relacionada com a baixa relação $\mathrm{C} / \mathrm{N}$ no primeir ro ano do experimento (Quadro 2), enquanto os al tos val ores de $\mathrm{N}$ liberados estão relacionados com a quantidade de matéria seca produzida.

No segundo ano, a maior taxa de decomposição e de liberação de $\mathrm{N}$ também ocorreu nos primeiros 42 dias, porém, em valores absolutos, os percentuais de decomposição foram menores do que no ano anterior, com destaque para a braquiária (37,2\%), milheto $(36,4 \%)$, sorgo $(28,6 \%)$, crotalária $(27,5 \%)$, pousio (22\%) e aveia-preta (19,1\%). Quanto à liberação de N, em valores absolutos, podem-se destacar a crotalária e o mil lheto, seguidos deguandu e braquiária (Quadro 5). A relação C/N das plantas de cobertura, quando comparada à do ano anterior, aumentou para todas as culturas, com exceção da aveia-preta que se manteve estável (Quadro 2).

\section{CONCLUSÕES}

1. O milheto foi a cobertura que apresentou a maior produção de massa seca. Dentre as leguminosas, a maior produção deMS foi verificada para a crotalária.

\section{Quadro 5. Liberação de nitrogênio acumulado dos resíduos vegetais no primeiro e no segundo ano de experimentação}

\section{Planta de cobertura $\mathbf{N}$ total acumulado}

Liberação de $\mathbf{N}$

110 a 152 DAP 152 a 208 DAP 208 a 264 DAP 264 a 320 DAP

\begin{tabular}{|c|c|c|c|c|c|}
\hline \multirow{2}{*}{ Pousio } & \multirow{2}{*}{46,6} & \multicolumn{4}{|c|}{$-\mathrm{kg} \mathrm{ha}^{-1}$} \\
\hline & & \multicolumn{4}{|c|}{ Primeiro ano (2000) } \\
\hline Milheto & 165,5 & 59,3 & 10,9 & 23,0 & 18,7 \\
\hline Sorgo & 84,1 & 31,8 & 11,4 & 9,8 & 5,4 \\
\hline Crotalária & 118,1 & 51,7 & 12,8 & 10,8 & 4,8 \\
\hline Aveia & 29,2 & 12,6 & 2,4 & 3,9 & 2,7 \\
\hline Guandu & 51,3 & 16,7 & 8,3 & 7,5 & 3,1 \\
\hline \multirow[t]{2}{*}{ Braquiária } & 130,8 & 77,4 & 10,3 & 14,9 & 13,2 \\
\hline & & \multicolumn{4}{|c|}{ Segundo ano (2001) } \\
\hline Pousio & 57,2 & 12,6 & 7,7 & 9,8 & 7,3 \\
\hline Milheto & 55,8 & 20,3 & 6,1 & 7,6 & 4,9 \\
\hline Sorgo & 45,0 & 12,9 & 5,6 & 9,4 & 3,9 \\
\hline Crotalária & 76,4 & 21,0 & 7,7 & 15,0 & 6,0 \\
\hline Guandu & 62,4 & 15,9 & 14,6 & 10,2 & 7,6 \\
\hline Braquiária & 41,7 & 15,5 & 8,7 & 6,5 & 4,6 \\
\hline
\end{tabular}

(1) DAP = Dias após plantio. 
2. As leguminosas (crotalária e guandu) apresentaram maior velocidade de decomposição quando comparadas às gramíneas.

3. A maior taxa de liberação de $\mathrm{N}$, para todas as coberturas, ocorreu 42 dias após a dessecação.

4. A velocidade de decomposição dos resíduos culturais ocorreu mais rapidamentenas parcelas em que foi cultivado milho.

\section{LITE RATURA CITADA}

AITA, C.; BASSO, C.J .; CERETTA, C.A.; GONÇALVES, C.N. \& ROS, C.O. Plantas de cobertura do solo como fonte de nitrogênio ao milho. R. Bras. Ci. Solo, 25:157-165, 2001.

BERG, B. Nitrogen release from litter and humus in coniferus forest soil - a mini review. Scand. J . For. Res., 1:359-369, 1986.

BERTOL, I.; CIPRANDI, O.; KURTZ, C. \& BAPTISTA, A.S. Persistência de resíduos culturais de aveia e milho sobre a superfície do solo em semeadura direta. R. Bras. Ci. Solo, 22:705-712, 1998.

BORKERT, C.M.; GAUDÊNCIO, C.A.; PEREIRA, J.E.; PEREIRA, L.R. \& OLIVEIRA J UNIOR, A. Nutrientes minerais na biomassa da parte aérea das culturas de cobertura de solo. Pesq. Agropec. Bras., 38:143-153, 2003.

CALEGARI, A.; FERRO, M.; GRZESIUK, F. \& J ACINTO J UNIOR, L. Plantio direto e rotação de culturas: experiência em Latossolo Roxo/1985-1992. Paraná, COCAMAR/ZENECA Agrícola, 1992, 64p.

CALEGARI, A.; MONDARDO, A.; BULISANI, E.A.; COSTA, M.B.B.; MIYSAKA, S. \& AMADO,T.J.C. Aspectos gerais da adubação verde. In: COSTA, M.B.B.; CALEGARI, A.; MONDARDO, A.; BULISANI, E.A.; WILDNER, L.P.; ALCÂNTARA, P.B.; MIYASAKA, S. \& AMADO, T.J.C. Adubação verde no sul do Brasil. 2.ed. Rio de J aneiro, ASPTA, 1993. p.56.

CARPENEDO, V. \& MIELNICZUK, J. Estado de agregação e qualidade de agregados de Latossolos Roxos, submetidos a diferentes sistemas de manejo. R. Bras. Ci. Solo, 14:99105, 1990.

CARVALHO, F.L.C.; COGO, N.P. \& LEVIEN, R. Eficácia relativa de doses e formas de manejo de resíduo culturas de trigo na redução da erosão hídrica do solo. R. Bras. Ci. Solo, 14:227-234, 1990

CHAVES, C.A.S. Produção e valor nutritivo das silagens de capim Sudão (Shorgum sudanense (Piper) Stapf), milheto (Pennisetum americanum (L.) Leeke), teosinto (Euchlaena mexicana Scharad) e milho (Zea mays L.). Lavras, Universidade Federal de Lavras, 1997, 56p. (Tese de Mestrado)

EMPRESA BRASILEIRA DE PESQUISA AGROPECUÁRIA EMBRAPA. Manual de métodos de análise de solo. 2.ed. Rio de J aneiro, 1997. 212p.

EMPRESA BRASILEIRA DE PESQUISA AGROPECUÁRIA EMBRAPA. Sistema Brasileiro de Classificação de Solos. Rio de J aneiro, 1999, 412 p.
ESPÍNDOLA, J.A.A.; GUERRA, J.G.M.; ALMEIDA, D.L.; TEIXEIRA, M.G.; URQUIAGA, S. \& PERIN, A. Decomposição in situ da parte aérea de algumas leguminosas perenes usadas como cobertura viva de solo. FERTBIO 98. In: REUNIÃO BRASILEIRA DE FERTILIDADE DO SOLO E NUTRIÇÃO DE PLANTAS, 23., Caxambu, 1988. Resumos. Caxambu, 1988. p.81.

EUCLIDES,R.F. Manual de utilização do programa SAEG (Sistema para Análises Estatísticas e Genéticas). Viçosa, Universidade Federal de Viçosa, 1983. 59p.

GONÇALVES, C.N. \& CERETTA, C.A. Plantas de cobertura de solo antecedendo o milho e seu efeito sobre o carbono orgânico do solo, sob plantio direto. R. Bras. Ci. Solo, 23:307313, 1999.

GUIMARÃES, G.L. Efeitos de culturas de inverno e do pousio na rotação de culturas de soja e do milho em sistema de plantio direto. Ilha Solteira, Universidade Estadual Paulista, 2000, 108p. (Tese de Mestrado)

HEINRICHS, R.; AITA, C.; AMADO, T.J .C. \& FANCELLI, A.L. Cultivo consorciado de aveia e ervilhaca: relação $\mathrm{C} / \mathrm{N}$ da fitomassa e produtividade do milho em sucessão. R. Bras. Ci. Solo, 25:331-340, 2001

HILDEBRAND, C. Manual de métodos de análise químicas de solo e plantas. Curitiba, Universidade Federal do Paraná, 1976. 225p. Não publicado.

HOLTZ, G.P. Dinâmica da decomposição da palhada e a distribuição do carbono, nitrogênio e fósforo numa rotação de culturas sob plantio direto na região de Carambeí/PR. Curitiba, Universidade Federal do Paraná, 1995, 129p. (Tese de Mestrado)

MELLILO, J .M.; ABER, J .D. \& MURATORE, J .F. Nitrogen and lignin control of hardwood leaf litter decomposition dynamics. Ecology., 63:621-626, 1982.

MORAES, R.N.S. Decomposição das pal hadas de sorgo e milheto, mineralização de nutrientes e seus efeitos no solo e na cultura do milho em plantio direto. Lavras, Universidade Federal de Lavras, 2001, 90p. (Tese de Mestrado)

MUZI LLI, O. Princípios e perspectivas de expansão. In: Plantio direto no Estado do Paraná. Londrina, IAPAR, 1981. p.1170.

OLIVEIRA, T.K. Plantas de cobertura em cultivo solteiro e consorciado e seus efeitos no feijoeiro e no solo em plantio direto. Lavras, UniversidadeF ederal de Lavras, 2001. 109p.

REICOSKY, D.C. \& FORCELLA, F. Cover crop and soil quality interactions in agroecosystems. J. Soil Water Conserv., 53:224-229, 1998.

REZENDE, C.P.; CANTARUTTI, R.B.; BRAGA, J .M.; GOMIDE, J.A.; PEREIRA, J.M.; FERREIRA,.E.; TARRE, R.; MACEDO,R.; ALVES, B.J.R.; URQUIAGA,S.; CADISCH,G.; GILLER, K.E. \& BODDEY, R.M. Litter deposition and disappearance in Brachiaria pastures in the Atlantic forest region of the South of Bahia, Brazil. Nutr. Cycling Agroecosys., 54:99-112, 1999.

SANTOS, P.F. \& WHILFORD, W.G. The effects of microarthropods on litter decomposition in a chihuazhuan ecosystem. E cology, 62:654-669, 1981. 
SCHUNKE, R.M. Qualidade, decomposição e liberação de nutrientes da liteira de quatro cultivares de Panicum maximun. Rio de J aneiro, Universidade Federal Rural do Rio de J aneiro, 1998, 88p. (Tese de Doutorado)

SILVA, M.L.N.; CURI, N.; BLANCANEAUX, P.; LIMA, J.M. \& CARVALHO, A.M. Rotação adubo verde- milho eadsorção de fósforo em Latossolo Vermelho-Escuro. Pesq. Agropec. Bras., 32:649-654, 1997.

SOUZA,W.J .O. \& MELO,W.J. Teores de nitrogênio no solo e nas frações da matéria orgânica sobre diferentes sistemas de produção de milho. R. Bras. Ci. Solo, 24:885-896, 2000.
SPAGNOLLO, E.; BAYER, C. WILDNER, L.P.; ERNANI, P.R.; ALBUQUERQUE, J .A. \& PROENÇA, M.M. Leguminosas estivais intercalares como fonte de nitrogênio para o milho no Sul do Brasil. R. Bras. Ci. Solo, 26:417-423, 2002.

TEDESCO, M.J .; VOLKWEISS, S.J . \& BOHNEN, H. Análise de solo, plantas e outros materiais. PortoAlegre, Faculdade de Agronomia, Universidade Federal do Rio Grande do Sul, 1985, 188p. (Boletim técnico de Solos, 5)

THOMAS, R.J . \& ASAKAWA, N.M. Decomposition of leaf litter from tropical forage grasses and legumes. Soil Biol. Biochem., 25:1351-1361, 1993. 